\title{
Study on the Integration and Development of Chinese Filial Piety Culture and Life Preserving Industry in Panzhihua
}

\author{
Xiying Fan \\ College of Foreign Languages \\ Pan Zhihua University \\ Pan Zhihua, China \\ 1352144980@qq.com
}

\begin{abstract}
Although there are many studies based on filial piety culture, the in-depth study and analysis of the combination of filial piety culture and Kang Yang industry are almost blank. In order to find the practical ways to integrate Chinese Filial Piety Culture into Life Preserving Industry in Panzhihua, the author, based on the literature review, has conducted in-depth investigation, and analyzed the development direction and inevitable choice of the old-age model from the perspective of modern filial culture, and proposed that we should seize the opportunity to integrate the filial piety culture into the planning and development of the Kangyang industry in Panzhihua, and pointed out specific integration paths and countermeasures, including creating a filial piety city, building a happy place for Kangyang, and refining the filial piety culture projects, developing filial products, creating a famous brand of sound mind and body, cultivating a health resort, building a "home"style health care service, using the Internet and modern technology to create a smart and healthy city, among which the last two measures, namely, the "building a "home"-style health care service and using the Internet and modern technology to create a smart and healthy city" are quite constructive and original.
\end{abstract}

Keywords-Chinese filial piety culture; Kangyang industry; Panzhihua; integrated development; research

\section{INTRODUCTION}

Filial piety culture is the jewel of Chinese culture and one of the most widely recognized values of the Chinese nation. The Chinese filial piety culture is an excellent traditional culture in which the Chinese nation reflects the respect, care, help and support of the elderly by individuals, families and society. China has entered and will be in an aging society for a long time. In the face of the wave of gray hair, the issue of oldage care has received more and more attention from society. The growing aging of China's population and the contradiction of the development of the old-age industry will become more and more prominent. Panzhihua City relies on the "six degrees" endowment suitable for humans to recuperate, such as altitude, temperature, humidity, cleanliness, superiority, and harmony. It is the first to propose the concept of "well-being", vigorously develop the "Kangyang plus" industry, and solve the bottleneck constraints of Panzhihua's current development. Old-age tourism, health care, and old-age care are just beginning markets. Under the wave of supply-side reform, vigorously developing the pension industry with the characteristics of "filial piety" is in line with the requirements of national industrial development and the actual social and economic development of Panzhihua. The Kangyang industry connects the economy and people's livelihood. There is no limit to future development. It is a veritable sunrise industry.

\section{THE NECESSITY OF THE INTEGRATION AND DEVELOPMENT OF CHINESE FILIAL PIETY CULTURE AND PANZHIHUA KANGYANG INDUSTRY}

\section{A. The Necessity of the Study}

Although there are many studies based on filial piety culture, the in-depth study and analysis of the combination of filial piety culture and Kang Yang industry are almost blank. After consulting the relevant literature, the research related to filial piety culture in China has the following focuses:

1) Focusing on the combination of traditional filial piety culture and specific cases

For example, $\mathrm{Xu}$ Yue[5] proposed to portray filial cultural resources (taking Chongyang Town filial culture tourism as an example), which is the basis for the development of filial culture tourism; in Chang Hongsheng's[1] research on "Dong Yong Resources", the development was discussed. "Dong Yong Resources" is conducive to promoting local economic development and building a harmonious society. The idea of "materializing Dong Yong resources and developing filial cultural tourism" was put forward; Taiwan scholars Zhan Jiahe and Chen Hongjun proposed the "story marketing" strategy of filial piety culture and studied Taiwanese enterprises to promote the generalization by refining "Mazu filial culture" Industrial development.

2) Focusing on the combination of filial piety culture and urban tourism brands

For example, from the aspects of functional value, brand value and relationship value, Jin Jinsong[6] studies the filial culture tourism branding model. From the perspective of city identification, Hu Jinlin[3] and other scholars have designed the strategic concept of Xiaogan to create a filial cultural city from the aspects of image, concept and management, and 
piety and form universal values to improve the overall quality of the citizens and promote social harmony.

The curriculum on filial piety culture will be added to help students further develop their understanding by explaining the origin and development of it. Secondly, the school can create a harmonious learning and education atmosphere by carrying out a variety of activities such as filial piety cultural activities, filial piety cultural knowledge contest. Thirdly, to promote the filial piety culture in public places such as the publicity column on campus, remind students to remember filial piety. By recommending the models of filial piety, we will publicize those who are filial to the elderly and those who are friendly to the neighbors. Through such influence, we can build a harmonious community. Combining family education with the education of Chinese culture to create cultural products that can educate, inspire consumers, and can be experienced.

2) Prosperity of filial piety art through creation of works with ethical and moral thoughts as the theme which keeps up with the times will make filial piety deeply rooted in people's hearts.

First, we can develop filial piety culture theme folk art boutique. The historical materials and folklore of the three filial sons of Dong Yong, Huang Xiang and Meng Zong can be organized into texts, relying on folk art (such as shadow, paper-cutting, festivals, etc.), combined with modern sound and light technology, with the combination of classical and modern art.. The second is to build a filial cultural performance center to create dramas, TV dramas or literary works about Dong Yong, Huang Xiang and Meng Zong, which will make the filial arts performing arts center more attractive and influential, and make filial piety deeply rooted into people's hearts.

\section{B. Refining and Creating Filial Piety Projects}

1) Constructing a Twenty-four Filial education base, the National Studies Museum, with "filial piety" as the core connotation, focusing on the stories of filial piety, the spirit of inheriting filial piety, and the practice of filial piety.

2) Combining family education with the education of Chinese culture to create cultural products that can educate, inspire consumers, and can be experienced.

3) Playing the Third-line Construction Museum card. The first we can guide the public to visit the Third-line Construction Museum, learn to carry forward the spirit of the third line, recall the selfless dedication of the older generation of Third-line builders, cultivate the respect and love for the older generation of builders, and bring them to life to form a respectful and filial love. Second, we can create youthful reunion events that recall the fierce battlefields of the three-line builders, attracting the older generation of Third-line Construction builders to bring their family and children and grandchildren to the old places for a revisit, bringing waves of Kangyang consumption.
1) With filial piety as the spirit of the city, we can carry out filial piety education and demonstrate the values of filial piety

We can guide and influence the public's thoughts and behaviors, prompting the public to respect and recognize filial 


\section{SUMMARY}

The government set up the stage, culture dominates, the company sings, and everyone participates. The school education reflects the characteristics of filial piety education, cultivates the volunteer team of "respecting the elderly" and "filial piety", and demonstrates the "positive energy" example of the society of respecting the elderly and filial piety. the allround development of the Kangyang industry, tourism, and regional specialty commodity industries and other industries can be promoted. By cultivating well-known brands and commodities rooted in filial piety culture, expanding employment, increasing income to improve the quality of the citizens, unite people's hearts, and publicize Panzhihua City. The popularity of the project will ultimately promote the economic and social development of the city. Carrying forward and inheriting the Chinese filial piety culture will promote the city's civilization construction, and will be widely recognized by the Kangyang people and their families. It will provide a steady stream of customers and old-age consumers for the development of the Panzhihua Kangyang industry, and further, stimulate the prosperity of this industry and help the long-term development of the city's economy.

\section{REFERENCES}

[1] C. Hongsheng, "Research on the principles and models of tourism development of Xiaoyong Dongyong Resources[J]. Journal of Technology Entrepreneurship, Vol. 22, No.10, pp. 59-60, 2009.(In Chinese).

[2] F. Dong. "On the interactive development of filial piety culture and social endowment security system”. Reform and Opening up, Vol. 4, pp. 149-150, 2011.(In Chinese).

[3] H. Jinlin. "Research on the development strategy of Xiaogan Filial Culture Industry Cluster”. Journal of Xiaogan University, Vol.30, No.1, pp. 24-28, 2010.(In Chinese).

[4] X. Tinghua, S. Wenzhou, Z. Xianzhang. "A brief discussion on the relationship between filial piety culture and clean government culture", Journal of Hubei Vocational and Technical College, Vol.14, No.4, pp. 64-66, 2011.(In Chinese).

[5] X. Yue., "Analysis on the development of traditional filial culture tourism resources-Taking the planning of Xiaoyang Town Xiaoxiong Tourism Park in Xixia County, Henan Province as an example, Huazhong Architecture, Vol. 31,.No.1, pp. 118-122, 2013.(In Chinese).

[6] Y. Jingsong "Research on the new model of brand building of piety Culture tourism products-Based on the Brand Theory proposed by Rust, Zeitham, and Lemon”, Journal of Hubei Vocational and Technical College, Vol. 17, No.2, pp. 85-88, 2014.(In Chinese) can be integrated into infrastructure construction to improve the convenience and intelligence of urban services; high-end medical enterprises can use Internet technology and intelligent management information systems to conduct remote health testing and guidance, develop new online courses, and open online health culture experience, get rid of the constraints of the region. Construction of the Panzhihua Kangyang website development of Kangyang APP, opening Kangyang Wechat interface, marketing of Kangyang products and services through e-commerce network. In the middle and late period of the construction of Kangyang City, the residents of the town can develop Kangyang e-commerce, spread their influence throughout China and even the international market through ecommerce, and build the brand image of vanadium and titanium products, subtropical fruits, winter flowers, and sunshine health. 